\title{
COMMUNICATIONS
}

\section{Probing a strong hydrogen bond with infrared spectroscopy: Vibrational predissociation of $\mathrm{BrHBr}^{-} \cdot \mathrm{Ar}$}

\author{
Nicholas L. Pivonka \\ Department of Chemistry, University of California, Berkeley, California 94720 and Chemical Sciences \\ Division, Lawrence Berkeley National Laboratory, Berkeley, California 94720
}

Cristina Kaposta and Mathias Brümmer

Institut für Experimentalphysik, Freie Universität Berlin, Arnimallee 14, D 14195 Berlin, Germany

Gert von Helden

FOM Institute for Plasmaphysics Rijnhuizen, Edisonbaan 14, NL-3439 MN, Nieuwegein, The Netherlands

Gerard Meijer

FOM Institute for Plasmaphysics Rijnhuizen, Edisonbaan 14, NL-3439 MN, Nieuwegein, The Netherlands; Department of Molecular and Laser Physics, University of Nijmegen, Toernooiveld, NL-6525 ED,

Nijmegen, The Netherlands; and Department of Molecular Physics, Fritz Haber Institute of the Max Planck Society, Faradayweg 4-6, Berlin, Germany

Ludger Wöste

Institut für Experimentalphysik, Freie Universität Berlin, Arnimallee 14, D 14195 Berlin, Germany

Daniel M. Neumark ${ }^{\mathrm{a})}$

Department of Chemistry, University of California, Berkeley, California 94720 and Chemical Sciences Division, Lawrence Berkeley National Laboratory, Berkeley, California 94720

Knut R. Asmis ${ }^{\text {a) }}$

Institut für Experimentalphysik, Freie Universität Berlin, Arnimallee 14, D 14195 Berlin, Germany

(Received 4 November 2002; accepted 21 January 2003)

\begin{abstract}
The gas phase vibrational spectroscopy of $\mathrm{BrHBr}^{-}$, a prototypical strongly hydrogen-bonded species, has been studied between 6 and $17 \mu \mathrm{m}\left(590\right.$ and $\left.1670 \mathrm{~cm}^{-1}\right)$ by infrared vibrational predissociation of the $\mathrm{BrHBr}^{-} \cdot \mathrm{Ar}$ ion. Infrared excitation was accomplished using the output of the free electron laser for infrared experiments (FELIX). Predissociation spectra were recorded by monitoring depletion of mass-selected $\mathrm{BrHBr}^{-} \cdot \mathrm{Ar}$ ions as a function of excitation wavelength. Four prominent absorption bands are observed at $733,890,1048$, and $1201 \mathrm{~cm}^{-1}$. They are assigned to the fundamental of the hydrogenic stretching mode $\nu_{3}$ and a sequence of $\nu_{3}+n \nu_{1}$ combinations $(n=1-3)$. Additional features to the blue of these bands spaced by $\sim 21 \mathrm{~cm}^{-1}$ are attributed to combination bands involving motion of the Ar messenger atom. Differences in the relative intensities of the $\nu_{3}+n \nu_{1}$ combinations bands in comparison to previous matrix experiments are rationalized on the basis of the underlying dissociation dynamics. (C) 2003 American Institute of Physics. [DOI: 10.1063/1.1559478]
\end{abstract}

Hydrogen bonding governs a number of diverse and important chemical interactions, ranging from the solvent properties of water and other liquids to the structure of proteins and nucleic acids. ${ }^{1}$ An important classification used in this context is based on the strength of the hydrogen bond, which is reflected in the distance between the heteroatoms sharing the hydrogen atom. As the bond strength increases, the distance between the heteroatoms as well as the hydrogen exchange barrier decreases. In the limit of strong or low-barrier hydrogen bonds, the barrier to hydrogen exchange has dropped below the zero point vibration, and the hydrogen assumes a symmetric position between the heteroatoms. These types of hydrogen bonds play an important role in both enzyme catalysis ${ }^{2,3}$ and proton exchange phenomena in acidic and basic aqueous solutions (e.g., $\mathrm{H}_{3} \mathrm{O}_{2}^{-}$and $\left.\mathrm{H}_{5} \mathrm{O}_{2}^{+}\right) ., 4$
The simplest strongly hydrogen-bonded species are the triatomic bihalide anions $\mathrm{XHX}^{-}$and $\mathrm{XHY}^{-}$. The vibrational spectroscopy of these anions has been studied extensively in cryogenic matrices. ${ }^{6}$ This work showed that the hydrogenic stretching frequencies were extremely low, ranging from $1330 \mathrm{~cm}^{-1}$ in $\mathrm{FHF}^{-}$to $645 \mathrm{~cm}^{-1}$ in $\mathrm{IHI}^{-}$, in contrast to the uncomplexed HX frequencies of $4138 \mathrm{~cm}^{-1}$ in $\mathrm{HF}$ and 2309 $\mathrm{cm}^{-1}$ in HI. ${ }^{7,8}$ This frequency shift is a direct consequence of extensive sharing of the central hydrogen between the two halogen atoms. However, these studies indicated that the effects of the matrix on the vibrational frequencies could be significant, providing strong motivation to measure the unperturbed gas phase infrared (IR) spectra of these bihalide anions. High resolution gas phase IR spectra over narrow frequency ranges have been measured for $\mathrm{FHF}^{-}$and $\mathrm{ClHCl}^{-}$ using diode laser absorption. ${ }^{9-12}$ In this paper, we report a 
different and more general approach to gas phase ion vibrational spectroscopy, combining excitation by means of a tunable infrared free electron laser [free electron laser for infrared experiments (FELIX)] with vibrational predissociation spectroscopy. ${ }^{13-15}$ The result is the first broadband infrared spectrum (from 590-1670 $\mathrm{cm}^{-1}$ ) of a gas phase bihalide anion, $\mathrm{BrHBr}^{-}$, measured by vibrational predissociation of $\mathrm{BrHBr}^{-} \cdot \mathrm{Ar}$.

The bihalide anion $\mathrm{BrHBr}^{-}$is believed to be symmetric $\left(D_{\infty h}\right),{ }^{6}$ and its high dissociation energy of $0.93 \mathrm{eV}$ makes it a model strong hydrogen bonding system. ${ }^{16}$ Inorganic salt and solution phase experiments yielded the first IR absorptions attributed to the $\mathrm{BrHBr}^{-}$complex in the region between 500 and $1300 \mathrm{~cm}^{-1} \cdot{ }^{17}$ Further IR absorption experiments performed by several groups in rare gas matrices assigned asymmetric stretch absorptions between 646 and $753 \mathrm{~cm}^{-1} \cdot{ }^{18-21}$ These experiments also yielded $\nu_{3}+n \nu_{1}$ combination bands, with $\left(\nu_{3}+\nu_{1}\right)-\nu_{3}$ values near 160 $\mathrm{cm}^{-1}$

Evaluation of the $\mathrm{BrHBr}^{-}$infrared spectrum through electronic structure calculations is complicated by the strong coupling between the vibrational modes. Del Bene and $J_{\text {Jordan }}^{22}$ have shown that vibrational frequencies determined by one-dimensional harmonic analysis are inadequate, regardless of the level of theory used in the calculation, and that it is instead necessary to construct a two-dimensional potential energy surface upon which energy levels involving symmetric and asymmetric stretch excitation can be computed accurately. Their calculated frequencies agree well with the earliest sets of Ar matrix results. ${ }^{18-20}$

For many years, the photoelectron spectrum of $\mathrm{BrHBr}^{-}$ has represented the only gas phase data on this anion. ${ }^{23,24}$ However, as part of a recent study of larger clusters, we performed tunable infrared multiphoton dissociation (IRMPD) experiments on $\mathrm{BrHBr}^{-}$using a free electron laser and observed a single broad peak near $1550 \mathrm{~cm}^{-1}$; this feature was tentatively assigned to the overtone of the $\nu_{3}$ vibrational mode. ${ }^{25}$ The IRMPD approach, which relies on a high density of states to overcome the anharmonic bottleneck in the multiphoton dissociation process, was less than ideal for bare $\mathrm{BrHBr}^{-}$with its relatively high $\mathrm{HBr}$ binding energy $\left(7480 \mathrm{~cm}^{-1}\right)$ and low number of vibrational degrees of freedom. ${ }^{16}$ Drawing on previous cation and anion spectroscopy experiments by Lee ${ }^{13}$ and Johnson, ${ }^{14,15}$ we present results here on the vibrational predissociation of $\mathrm{BrHBr}^{-} \cdot \mathrm{Ar}$. The Ar atom acts as a "messenger" or "spy" atom, and its expected low binding energy allows detection of the absorption of a single IR photon via vibrational predissociation:

$$
\begin{aligned}
\operatorname{BrHBr}^{-} \cdot \operatorname{Ar}\left(\nu_{3}=0\right) & \stackrel{h \nu}{\rightarrow} \mathrm{BrHBr}^{-} \cdot \mathrm{Ar}\left(\nu_{3}=1\right) \\
& \rightarrow \mathrm{Ar}+\mathrm{BrHBr}^{-}
\end{aligned}
$$

By monitoring depletion of the $\mathrm{BrHBr}^{-} \cdot \mathrm{Ar}^{-}$complex or production of $\mathrm{BrHBr}^{-}$as a function of excitation energy, the vibrational spectrum of $\mathrm{BrHBr}^{-}$can be obtained.

The present experiments were carried out on a previously described tandem mass spectrometer ion trap system. ${ }^{26}$ Briefly, $\mathrm{BrHBr}^{-} \cdot \mathrm{Ar}$ cluster anions are created by crossing a pulsed supersonic expansion of $\sim 0.1 \% \mathrm{HBr}$ in $\mathrm{Ar}$ with a 300 $\mu \mathrm{A}, 1 \mathrm{keV}$ electron beam. The supersonic expansion is generated by a pulsed valve operating at $100 \mathrm{~Hz}$ with a backing pressure of $5 \mathrm{bar}$. The anions pass through a $2 \mathrm{~mm}$ skimmer, are collimated by a linear radio frequency $(\mathrm{RF})$ ion guide, then mass-selected by a quadrupole mass spectrometer. Subsequently the mass-selected ions are collected in a He filled linear RF hexadecapole ion trap which is connected to a helium cryostat and kept at a temperature of $<70 \mathrm{~K}$. Collisions with the He buffer gas $(\sim 0.03 \mathrm{mbar})$ slow the ions and cool them to the ambient temperature. Roughly $80 \%$ of the ("fast") $\mathrm{BrHBr}^{-} \cdot \mathrm{Ar}$ ions entering the ion trap fragment through collisions with the $\mathrm{He}$ atoms, forming $\mathrm{BrHBr}^{-}$. Because of this wavelength independent $\mathrm{BrHBr}^{-}$background signal, a better signal-to-noise ratio is achieved by monitoring $\mathrm{BrHBr}^{-} \cdot \mathrm{Ar}$ depletion rather than the $\mathrm{BrHBr}^{-}$formation.

The ion trap is continuously filled for $160 \mathrm{~ms}$. Trapped ions interact with a single macropulse of the $5 \mathrm{~Hz}$ output of FELIX, composed of $5 \mu$ s long macropulses, with each macropulse comprising a series of $\sim 1 \mathrm{ps}$ micropulses separated by a nanosecond. ${ }^{27}$ Pulse energies used in these experiments were on the order of $15 \mathrm{~mJ} /$ macropulse, with a Gaussian bandwidth of $\sim 0.8 \%$ of the central energy (FWHM). The output of FELIX was introduced into the ion trap region through a $\mathrm{KBr}$ lens (focal length $478 \mathrm{~mm}$ ) and a $5 \mathrm{~mm}$ thick $\mathrm{KBr}$ window. Focusing of the FELIX beam is required to avoid light scattering off the ion trap exit and entrance lenses. One millisecond after irradiation, the ion trap is emptied, and the $\mathrm{BrHBr}^{-} \cdot \mathrm{Ar}$ signal is mass-selectively monitored using a (second) quadrupole mass spectrometer. The ion trap is then refilled again and the cycle repeated multiple times at each wavelength step in order to assure sufficient signal averaging.

Infrared predissociation spectra of ${ }^{81} \mathrm{BrH}^{81} \mathrm{Br}^{-} \cdot \mathrm{Ar}$ are shown in Fig. 1. Observed peak positions and assignments are listed in Table 1. Overview scans (main spectrum) were measured from 6 to $17 \mu \mathrm{m}$ with a step size of $0.1 \mu \mathrm{m}$. Higher resolution spectra (step size: $0.01-0.02 \mu \mathrm{m}$ ) were measured with an increased number of shots per data point in selected regions and are shown in the inset. Four prominent depletion features are readily identifiable at 733, 890, 1048 and $1201 \mathrm{~cm}^{-1}$. Gaussian peak widths (FWHM) were found to be $15,13,11$, and $10 \mathrm{~cm}^{-1}$ and are chiefly limited by the bandwidth of FELIX. An assignment of these features based on the previous matrix experiments is straightforward (see Tables 1 and 2). The peak at $733 \mathrm{~cm}^{-1}$ is assigned to the fundamental of the $\mathrm{BrHBr}^{-} \nu_{3}$ mode and the sequence observed at shorter wavelengths to $\nu_{3}+n \nu_{1}(n=1-3)$ combinations bands involving the symmetric stretch vibration. Weaker features are observed in the (smoothed) higher resolution spectra at 754, 775, 911, 929 and $1070 \mathrm{~cm}^{-1}$, which we attribute to combination bands involving excitation of the Ar motion with a characteristic fundamental frequency of 21 $\mathrm{cm}^{-1}$. There is also suggestion of a weak depletion feature near $650 \mathrm{~cm}^{-1}$, in the anticipated region of the $\nu_{2}$ fundamental, but further study will be necessary to confirm this observation.

In the overview spectra, depletion of the parent ion signal is as high as $\sim 75 \%$, with baseline fluctuations on the 
TABLE I. Observed depletion features, bandwidths and assignments.

\begin{tabular}{ccc}
\hline \hline $\begin{array}{c}\text { Frequency } \\
\left(\mathrm{cm}^{-1}\right)\end{array}$ & $\begin{array}{c}\text { Width } \\
\left(\mathrm{cm}^{-1}\right)\end{array}$ & Assignment \\
\hline 733 & 15 & $1 \nu_{3}$ \\
754 & & $1 \nu_{3}+1 \nu_{\mathrm{Ar}}$ \\
775 & 13 & $1 \nu_{3}+2 \nu_{\mathrm{Ar}}$ \\
890 & & $1 \nu_{3}+1 \nu_{1}$ \\
911 & & $1 \nu_{3}+1 \nu_{1}+1 \nu_{\mathrm{Ar}}$ \\
929 & 11 & $1 \nu_{3}+1 \nu_{1}+2 \nu_{\mathrm{Ar}}$ \\
1048 & & $1 \nu_{3}+2 \nu_{1}+1 \nu_{\mathrm{Ar}}$ \\
1070 & 10 & $1 \nu_{3}+3 \nu_{1}$ \\
1202 & 10 & \\
\hline \hline
\end{tabular}

order of 5\%-10\%. The fluctuations are mainly a result of variations in source conditions. No $\mathrm{Br}^{-}$ions were observed over the entire scan region, indicating (a) no collisionally induced rupture of the hydrogen bond and (b) no IRMPD processes resulting in $\mathrm{BrHBr}^{-}$breakdown. No features are found at the location of the previously assigned overtone near $1550 \mathrm{~cm}^{-1}$, calling that assignment into question. ${ }^{25}$

A comparison of the experimental peak energies and those calculated by Del Bene and Jordan ${ }^{22}$ for the $\nu_{3}+n \nu_{1}$ series $(n=0-3)$ is shown in Table 2. The calculated and experimental $\nu_{3}$ fundamentals $\left(731\right.$ and $733 \mathrm{~cm}^{-1}$ ) are in excellent agreement. The absolute deviations across the series are small $\left(\leqslant 10 \mathrm{~cm}^{-1}\right)$, so the assignment of the experimental peaks to this series is straightforward. The experimental peak spacings between adjacent peaks are 157, 158 and $154 \mathrm{~cm}^{-1}$ for $n=0-1,1-2$, and 2-3, i.e., decreasing slightly with increasing $n$. These spacings are $4-6 \mathrm{~cm}^{-1}$ less than the corresponding spacings between the calculated peak positions in Table 2. One of the more striking features of the calculation by Del Bene and Jordan was that the spacing between the peaks of the $\nu_{3}+n \nu_{1}$ series was $20-30 \mathrm{~cm}^{-1}$ less than the calculated energy of the $\nu_{1}$ fundamental, 189 $\mathrm{cm}^{-1}$, indicating that antisymmetric stretch excitation reduces the symmetric stretch frequency, and the overall agreement between experiment and theory in Table 2 supports this conclusion. The very presence of the $\nu_{3}+n \nu_{1}$ sequence further demonstrates the breakdown of the harmonic approximation in the presence of a strong hydrogen bond such as this one, and emphasizes the need for explicit consideration of intermode coupling when calculating the properties of strongly hydrogen bonded systems. ${ }^{28,29}$

TABLE II. Comparison of experimental and calculated vibrational frequencies for the BrHBr-complex ion.

\begin{tabular}{|c|c|c|c|c|c|c|}
\hline Assignment & Gas phase & $\begin{array}{c}\text { Matrix } \\
\mathrm{Ne}^{\mathrm{a}}\end{array}$ & $\begin{array}{c}\text { Matrix } \\
\mathrm{Ar}^{\mathrm{b}}\end{array}$ & $\begin{array}{c}\text { Matrix } \\
\mathrm{Kr}^{\mathrm{c}}\end{array}$ & $\begin{array}{c}\text { Matrix } \\
\mathrm{Xe}^{\mathrm{c}}\end{array}$ & Calculated $^{\mathrm{d}}$ \\
\hline$\nu_{3}$ & 733 & 741 & 728 & 687 & 646 & 731 \\
\hline$\left(\nu_{3}+1 \nu_{1}\right)-\nu_{3}$ & +157 & +163 & +164 & +158 & +152 & +162 \\
\hline$\left(\nu_{3}+2 \nu_{1}\right)-\nu_{3}$ & +315 & & +325 & +313 & +300 & +323 \\
\hline$\left(\nu_{3}+3 \nu_{1}\right)-\nu_{3}$ & +469 & & & +466 & +446 & +481 \\
\hline
\end{tabular}

${ }^{\mathrm{a}}$ Reference 16.

${ }^{\mathrm{b}}$ Reference 17

${ }^{c}$ Reference 18 .

${ }^{\mathrm{d}}$ Reference 19.

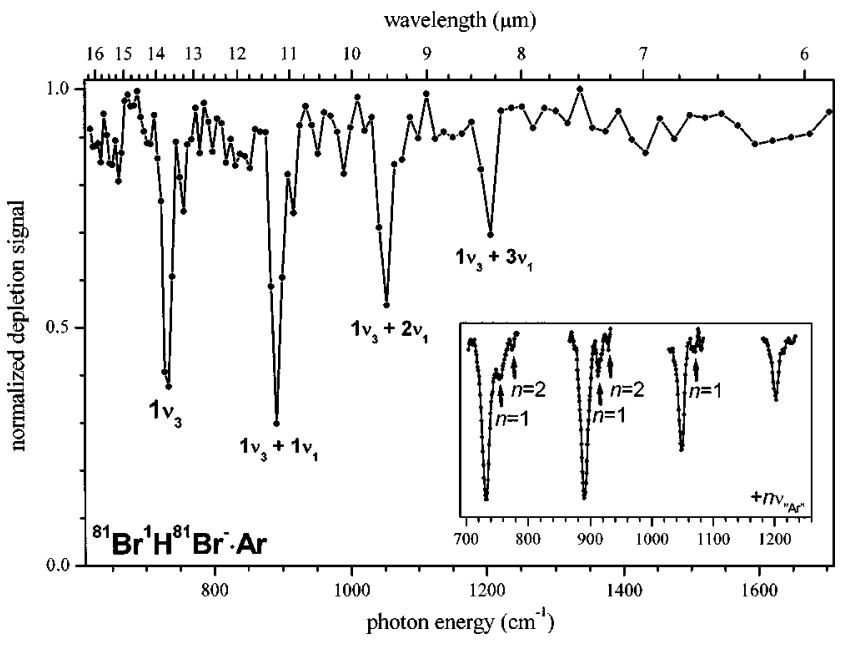

FIG. 1. Infrared predissociation overview spectrum of ${ }^{81} \mathrm{BrH}^{81} \mathrm{Br}^{-} \cdot \mathrm{Ar}$ measured by monitoring the depletion of the parent ion. Inset shows smoothed (3-point average) spectra measured with smaller step size (see text).

The depletion peak intensities in Fig. 1 differ significantly from the intensities previously observed in matrix IR absorption experiments, in which the absorption decreased by a factor of two from $\nu_{3}$ to $\nu_{3}+\nu_{1}$ and a factor of ten from $\nu_{3}$ to $\nu_{3}+2 \nu_{1} \cdot{ }^{18-21}$ The depletion intensities observed in the present experiment cannot be directly compared to the absorption intensities reported in the previous matrix studies, since the depletion signal reflects not only the oscillator strengths of the IR transitions, but also (a) the variation in FELIX power and bandwidth over the scan range and (b) the cluster predissociation rate. FELIX characteristics were optimized such that power and bandwidth change as little as possible in the energy range of interest. It is more likely that the dissociation rate of the vibrationally excited clusters influences the intensity distribution, with a lower dissociation rate for less vibrationally excited anions resulting in a smaller than expected relative depletion signal.

In order for the dissociation rate to effect peak intensities, the dissociation lifetime must be at least a few microseconds, since this is the time scale for collisions between the trapped ions and the He buffer gas inside the trap. The ions are extracted $1 \mathrm{~ms}$ after the irradiation pulse, so it can be assumed that all photoexcited ions have either dissociated or been collisionally quenched before the extraction pulse is applied to the ion trap exit lens. It thus appears that the cluster predissociation rate increases with excitation of the symmetric stretch of the $\mathrm{BrHBr}^{-}$chromophore. This could be a "total energy" effect, in which the total excess energy above the dissociation threshold (estimated ${ }^{30-32}$ to be $300-$ $400 \mathrm{~cm}^{-1}$ ) determines the dissociation rate. Alternatively, the predissociation rate may be mode-specific, with $\nu_{1}$ excitation promoting dissociation more efficiently than $\nu_{3}$ excitation.

The combination of vibrational predissociation spectroscopy with FELIX excitation opens up a new frontier in the study of hydrogen bonded ions. The effect of solvation upon the hydrogen bond is of particular interest. Simulations based on pairwise sums of empirical potentials carried out by McCoy and co-workers predict a $\nu_{3}$ shift of only $-1 \mathrm{~cm}^{-1}$ upon addition of an $\mathrm{Ar}$ atom to $\mathrm{ClHCl}^{-} .{ }^{33}$ Vibrational predissocia- 
tion experiments by Kelley et al. ${ }^{34}$ on $\mathrm{Cl}^{-} \cdot \mathrm{H}_{2} \mathrm{O} \cdot \mathrm{Ar}_{\mathrm{n}}$ found a sequential shift in the hydrogen bonded $\mathrm{OH}$ stretch of less than $3 \mathrm{~cm}^{-1}$ upon addition of $1-5 \mathrm{Ar}$ atoms. Hence, the addition of a single Ar atom is expected to result in a negligible shift of the $\mathrm{BrHBr}^{-}$frequency from its gas phase value. On the other hand, vibrational ${ }^{25}$ and photoelectron ${ }^{35}$ spectroscopy have shown that the addition of a single $\mathrm{HBr}$ to $\mathrm{BrHBr}^{-}$profoundly alters the anionic hydrogen bond, resulting in a structure more akin to $\mathrm{Br}^{-}(\mathrm{HBr})_{2}$. The photoelectron spectrum of $\mathrm{BrHBr}^{-}\left(\mathrm{H}_{2} \mathrm{O}\right)$ suggests an intermediate degree of hydrogen bond perturbation by the water molecule. ${ }^{35}$ This inference can be tested more directly through measurement of the IR spectrum of this species, an experiment planned for the very near future. The determination of vibrational frequencies in bihalide anions can also be exploited in transition state spectroscopy experiments in which the photoelectron spectrum of a vibrationally excited state is measured, because photodetachment of vibrationally excited anions will allow for Franck-Condon overlap with a larger region of the neutral $\mathrm{X}+\mathrm{HY}$ hydrogen exchange transition state region than can be accessed by photodetachment of ground state anions. ${ }^{36,37}$

This work is supported by the Sonderforschungsbereich 546 and the Ph.D. Graduate Study Program 788 of the DFG. United States AFOSR Grant No. F49620-00-1-0018 provided support for N.L.P and D.M.N. We gratefully acknowledge the support of the Stichting voor Fundamenteel Onderzoek der Materie (FOM) in providing the required beam time on FELIX and highly appreciate the skillful assistance of the FELIX staff, in particular Dr. A. F. G. van der Meer.

a) Authors to whom correspondence should be addressed. Electronic mail: dan@radon.cchem.berkeley.edu and asmis@physik.fu-berlin.de

${ }^{1}$ G. C. Pimentel and A. L. McClellan, The Hydrogen Bond (W. H. Freeman, San Francisco, 1960).

${ }^{2}$ P. A. Frey, S. A. Whitt, and J. B. Tobin, Science 264, 1927 (1994).

${ }^{3}$ W. W. Cleland and M. M. Kreevoy, Science 264, 1887 (1994).

${ }^{4}$ M. E. Tuckerman, D. Marx, M. L. Klein, and M. Parrinello, Science 275, 817 (1997).

${ }^{5}$ C. C. M. Samson and W. Klopper, J. Mol. Struct.: THEOCHEM 586, 201 (2002).
${ }^{6}$ B. S. Ault, Acc. Chem. Res. 15, 103 (1982).

${ }^{7}$ D. U. Webb and K. N. Rao, J. Mol. Spectrosc. 28, 121 (1968).

${ }^{8}$ D. R. J. Boyd and H. W. Thompson, Spectrochim. Acta 5, 308 (1952).

${ }^{9}$ K. Kawaguchi and E. Hirota, J. Chem. Phys. 84, 2953 (1986).

${ }^{10}$ K. Kawaguchi and E. Hirota, J. Chem. Phys. 87, 6838 (1987).

${ }^{11}$ K. Kawaguchi, J. Chem. Phys. 88, 4186 (1988).

${ }^{12}$ K. Kawaguchi and E. Hirota, J. Mol. Struct. 352, 389 (1995).

${ }^{13}$ M. Okumura, L. I. Yeh, and Y. T. Lee, J. Chem. Phys. 83, 3705 (1985).

${ }^{14}$ C. G. Bailey, J. Kim, C. E. H. Dessent, and M. A. Johnson, Chem. Phys. Lett. 269, 122 (1997).

${ }^{15}$ P. Ayotte, C. G. Bailey, G. H. Weddle, and M. A. Johnson, J. Phys. Chem. A 102, 3067 (1998).

${ }^{16}$ G. Caldwell and P. Kebarle, Can. J. Chem. 63, 1399 (1985).

${ }^{17}$ J. C. Evans and G. Y. S. Lo, J. Phys. Chem. 71, 3942 (1967).

${ }^{18}$ V. Bondybey, G. C. Pimentel, and P. N. Noble, J. Chem. Phys. 55, 540 (1971).

${ }^{19}$ C. L. Lugez, M. E. Jacox, and W. E. Thompson, J. Chem. Phys. 105, 3901 (1996).

${ }^{20}$ D. E. Milligan and M. E. Jacox, J. Chem. Phys. 55, 2550 (1971).

${ }^{21}$ M. Rasanen, J. Seetula, and H. Kunttu, J. Chem. Phys. 98, 3914 (1993).

${ }^{22}$ J. E. Del Bene and M. J. T. Jordan, Spectrochim. Acta, Part A 55, 719 (1999).

${ }^{23}$ R. B. Metz, A. Weaver, S. E. Bradforth, T. N. Kitsopoulos, and D. M. Neumark, J. Phys. Chem. 94, 1377 (1990).

${ }^{24}$ R. B. Metz and D. M. Neumark, J. Chem. Phys. 97, 962 (1992).

${ }^{25}$ N. L. Pivonka, C. Kaposta, G. von Helden, G. Meijer, L. Woste, D. M. Neumark, and K. R. Asmis, J. Chem. Phys. 117, 6493 (2002).

${ }^{26}$ K. R. Asmis, M. Brümmer, C. Kaposta, G. Santambrogio, G. von Helden, G. Meijer, K. Rademann, and L. Wöste, Phys. Chem. Chem. Phys. 4, 1101 (2002).

${ }^{27}$ D. Oepts, A. F. G. Vandermeer, and P. W. Vanamersfoort, Infrared Phys. Technol. 36, 297 (1995).

${ }^{28}$ M. V. Vener, O. Kuhn, and J. Sauer, J. Chem. Phys. 114, 240 (2001).

${ }^{29}$ J. E. Del Bene and M. J. T. Jordan, J. Mol. Struct.: THEOCHEM 573, 11 (2001).

${ }^{30}$ Y. X. Zhao, I. Yourshaw, G. Reiser, C. C. Arnold, and D. M. Neumark, J. Chem. Phys. 101, 6538 (1994).

${ }^{31}$ K. R. Asmis, T. R. Taylor, C. S. Xu, and D. M. Neumark, J. Chem. Phys. 109, 4389 (1998).

${ }^{32}$ Z. Liu, H. Gomez, and D. M. Neumark, Chem. Phys. Lett. 332, 65 (2000).

${ }^{33}$ H. B. Lavender and A. B. McCoy, J. Phys. Chem. A 104, 644 (2000).

${ }^{34}$ J. A. Kelley, J. M. Weber, K. M. Lisle, W. H. Robertson, P. Ayotte, and M. A. Johnson, Chem. Phys. Lett. 327, 1 (2000).

${ }^{35}$ H. Gomez, A. Meloni, J. Madrid, and D. M. Neumark, J. Chem. Phys. (to be published).

${ }^{36}$ S. E. Bradforth, A. Weaver, D. W. Arnold, R. B. Metz, and D. M. Neumark, J. Chem. Phys. 92, 7205 (1990).

${ }^{37}$ D. M. Neumark, PhysChemComm 5, 76 (2002). 